\title{
Caveolin 1 protein expression in renal cell carcinoma predicts survival
}

\author{
Sandra Steffens ${ }^{1 * \dagger}$, Andres J Schrader ${ }^{2 \dagger}$, Hanna Blasig ${ }^{1}$, Gesa Vetter ${ }^{1}$, Hendrik Eggers ${ }^{1}$, Wolfgang Tränkenschuh ${ }^{3}$, \\ Markus A Kuczyk ${ }^{1}$ and Jürgen Serth ${ }^{1}$
}

\begin{abstract}
Background: Caveolae play a significant role in disease phenotypes such as cancer, diabetes, bladder dysfunction, and muscular dystrophy. The aim of this study was to elucidate the caveolin-1 (CAV1) protein expression in renal cell cancer (RCC) and to determine its potential prognostic relevance.
\end{abstract}

Methods: 289 clear cell RCC tissue specimens were collected from patients undergoing surgery for renal tumors. Both cytoplasmic and membranous CAV1 expression were determined by immunohistochemistry and correlated with clinical variables. Survival analysis was carried out for 169 evaluable patients with a median follow up of 80.5 months (interquartile range (IQR), 24.5 - 131.7 months).

Results: A high CAV1 expression in the tumor cell cytoplasm was significantly associated with male sex ( $p=0.04)$, a positive nodal status $(p=0.04)$, and poor tumor differentiation $(p=0.04)$. In contrast, a higher than average (i.e. $>$ median) CAV1 expression in tumor cell membranes was only linked to male sex $(p=0.03)$. Kaplan-Meier analysis disclosed significant differences in 5-year overall (51.4 vs. $75.2 \%, p=0.001$ ) and tumor specific survival (55.3 vs. $80.1 \%, p=0.001$ ) for patients with higher and lower than average cytoplasmic CAV1 expression levels, respectively. Applying multivariable Cox regression analysis a high CAV1 protein expression level in the tumor cell cytoplasm could be identified as an independent poor prognostic marker of both overall $(p=0.02)$ and tumor specific survival ( $p=0.03$ ) in clear cell RCC patients.

Conclusion: Over expression of caveolin-1 in the tumour cell cytoplasm predicts a poor prognosis of patients with clear cell RCC. CAV1 is likely to be a useful prognostic marker and may play an important role in tumour progression. Therefore, our data encourage further investigations to enlighten the role of CAV1 and its function as diagnostic and prognostic marker in serum and/or urine of RCC patients.

\section{Background}

Renal cell carcinoma (RCC) is a common urologic tumor and accounts for about 3\% of all human malignancies. A significant increase in its incidence has been observed during the last decades, and the annual mortality-to-incidence ratio for RCC is considerably higher than for other tumors of the genitourinary tract [1].

Tumor characteristics such as tumor stage and grade seem to have limited value in predicting the clinical outcome of individual patients as around $50 \%$ of patients who undergo surgery with curative intent for less

\footnotetext{
* Correspondence: steffens.sandra@mh-hannover.de

+ Contributed equally

'Department of Urology, Hannover Medical School, (Carl-Neuberg-Strasse 1), Hannover, (30625), Germany

Full list of author information is available at the end of the article
}

advanced disease can be expected to develop a distant recurrence. Moreover, RCC encompasses many histological subtypes with distinct genetic and biologic features that determine clinical course and outcome [2]. Therefore, an increased understanding of genetic and biologic changes could help to develop a valuable marker to improve the individual therapeutic management and clinical outcome of RCC.

An essential step in the formation of metastases is the invasion of tumor cells into the extra cellular matrix. Cell adhesion molecules and extra-cellular matrix proteins can either support an increase or a decrease in the ability of tumor cells to adhere to surrounding tissue. Caveolin-1 (CAV1) has been identified two decades ago; it has been proposed to act as a tumor suppressor protein, inhibiting the functional signaling activity of several proto-oncogenes 
and consequently disrupting the process of cellular transformation [3-12]. Numerous follow-up studies designed to test this hypothesis have contributed a myriad of evidence suggesting that CAV1 may indeed possess tumor suppressor capabilities. For instance, CAV1 mRNA and protein expressions are down regulated in NIH-3T3 cells transformed with several activated oncogenes, such as $\mathrm{v}$-Abl, Bcr-Abl, and H-Ras (G12V) [3,9]. Genetic evidence supporting the role of CAV1 as a tumor suppressor has emerged from gene mapping studies, which revealed that the human CAV-1 gene maps to the long arm of human chromosome 7 (7q31.1). However, a number of clinicopathologial studies have shown a positive correlation between CAV1 over expression and advanced renal cell cancer, metastasis and poor prognosis [13]. In addition, these studies yielded variable and even contradicting results in terms of over expression in different histological subtypes [2].

The aim of this study was to elucidate the expression of CAV1 in RCC and to determine its potential prognostic relevance for patients with clear cell cancer.

\section{Methods}

\section{Tissue specimens}

The present study included 289 patients, who underwent radical nephrectomy between 1979 and 1998 in the Hannover Medical School. The ethical committee of the institution approved the study. Tissue was obtained from archival routine surgical specimens. The tissue samples were selected by a pathologist and prepared from the primary tumor and arranged on tissue micro arrays (TMA) as described previously [14]. Two pathologists evaluated all specimens with respect to tumor stage, grade, and histological subtypes. Tumour samples were classified primarily according to UICC 1997 TNM tumour staging system [15] and nuclear grading was based on the Fuhrman grading system [16]. Histological subtypes were assessed according to the consensus classification of renal cell neoplasia [17]. Data were collected by physicians and data managers and subsequently maintained by a relational database.

\section{Patients}

The median age of the cohort was 60.4 years $(S D \pm 11.3$ months). 159 patients were men (55\%), and 130 patients were women (45\%). 8, 150, 115, and 16 presented with pT1, pT2, pT3 and pT4 cancer, respectively. Tumour differentiation showed that 50, 181, 21 suffered from G1, G2, and G3/4 tumours. Furthermore, 29 patients presented with lymph node and 55 patients with visceral metastasis.

In the majority of cases, data regarding the cancerspecific long-term survival (CSS) were retrieved from electronic patient charts. The duration of the follow-up was calculated from date of surgery to the date of death or last follow-up. Death was assessed as either cancerrelated or unrelated. Survival analysis was carried out for 169 evaluable patients with complete follow-up data and pathologically proven clear cell carcinoma of the kidney. The follow up group $(n=169)$ exhibited a median follow-up period of 80.5 months (IQR, 24.5 - 131.7 months). At the time of the last follow-up examination, 80 of patients were alive, 63 patients had died from progressive RCC and 26 patients due to other causes.

\section{Procedures}

Expression of CAV1 was determined by immunohistochemistry (IHC). The paraffin-embedded TMA samples were deparaffinized, rehydrated and immersed in 3\% hydrogen peroxide solution to block endogenous peroxidase activity. Antigen retrieval was accomplished by microwave heating specimens in a $0.01 \mathrm{M}$ citrate buffer for 15 min. Biomarker expression was immunohistochemically detected by commercially available antibodies (CAV1 rabbit polyclonal anti-caveolin-1 dilution 1:100, Becton Dickinson Biosciences, Franklin Lakes, NJ, USA). After 12 $h$ of incubation the sections were washed in TBS and incubated with a secondary biotinylated antibody (Vectastatin Elite ABC Kit, Vector Laboratories, Inc., Burlingame, CA, USA) for $60 \mathrm{~min}$. and visualization using the DAB systems according to the manufacturer's instructions. Sections were briefly rinsed in tap water, counterstained with Mayer's Haematoxylin solution and then mounted. For negative control, the primary antibody was replaced by non-immune serum. All tissue staining were assessed in a blind study by two independent investigators (H.B and S. W.).

The rabbit polyclonal anti-caveolin-1 from Becton Dickinson Biosciences (Franklin Lakes, NJ, USA) recognises both the $\mathrm{a}$ and $\mathrm{b}$ isoforms of caveolin- 1 as assessed by Western blotting. Negative controls run in parallelcomprised sections where the primary antibody had been omitted. Caveolin-1 staining of peripheral endothelial cells and non-neoplastic tissue adjacent to the tumour were used as the positive controls (also see additional file 1, figure S1). In negative controls the primary antibody was omitted.

The expression of CAV1 was evaluated in the membrane, cytoplasm and nucleus of the tumour cells. The staining reaction was classified according to a semiquantitative IHC reference scale as previously described [18-22]. Membranous CAV1 expression was scored using the internal vascular endothelial cells as the positive control. Staining stronger than, equivalent to, or weaker than the vascular endothelial cells was scored as 3,2 and 1 , respectively, and the absence of staining was scored as 0 [13] (also see additional file 2, figure S2). In 
addition, cytoplasmic CAV1 staining stronger than, equivalent to, or weaker than the vascular endothelial cells was scored as 5, 3 and 1, respectively; and the absence of staining was scored as 0 . Furthermore, the scores 4 and 2 describing staining partly classified as 5 and 3 and 3 and 1, respectively, were added. Adding the stained area $(1=0-5 \%, 2=6-25 \%, 3=26-50 \%, 4=51$ $75 \%$ and $5=76-100 \%$ ) a novel staining intensity score was defined by multiplying the score with the stained area. Given the absence of normative data on cell membrane or cell cytoplasma staining intensity in the literature, values in our patient collective were dichotomized using the median of observed distribution as the cut off.

\section{Statistical analysis}

The primary endpoints of this study were tumor specific and overall-survival. Continuous variables were reported as means and standard deviations (SD) for parametric distributions or as medians and interquartile ranges (IQRs) for nonparametric distributions. Kaplan-Meier survival times were calculated, and subgroups were compared by the log-rank test statistic. Multivariate Cox regression models were used to assess the association between survival and cell membrane as well as cytoplasmic CAV1 expression adjusted for different clinical and patient covariates. The chi-square test and Fisher's exact test were conducted to assess associations between cell membrane/cytoplasm and patient/tumor specific characteristics. SPSS 17.0 was used for statistical assessment. P values below 0.05 were considered significant in all tests. All p values were two-sided.

\section{Results \\ Correlation between patient characteristics and CAV1 expression}

CAV1 expression was detected in the tumor cell cytoplasm of $242(83.7 \%)$ and the tumor cell membrane of $232(80.3 \%)$ patients with clear cell RCC. The median staining intensity was 3 (range: 1-25, IQR: 1-9) for tumor cell cytoplasm, and 3 (range: 1-15, IQR: 1-6) for tumor cell membranes, respectively. CAV1 protein expression in the tumor cell cytoplasm and cell membrane correlated moderately but significantly $(\mathrm{r}=0.52, \mathrm{p}$ $<0.001$, Pearson). The cell nuclei were CAV1 negative in all patients' tumor specimens.

A high CAV1 expression in the tumor cell cytoplasm was significantly associated with male sex $(\mathrm{p}=0.044)$, a positive nodal status ( $\mathrm{p}=0.042)$, and poor tumor differentiation ( $\mathrm{p}=0.035$; table 1$)$. In contrast, a higher than average (i.e. $>$ median or $>3$ intensity score) CAV1 expression in tumor cell membranes was only linked to male sex ( $p=0.03$; table 2$)$. There was no significant correlation between CAV1 staining and patient age, tumor stage, and visceral metastasis.

\section{CAV1 expression predicts the clinical course}

The calculated median five-year overall and tumor specific survival ratio of all 169 evaluable patients was 65.0\% and 69.5\% months, respectively.

With a median follow-up of 80.5 months (IQR, 24.5 131.7 months), a higher disease-related death rate was observed among patients with higher-than-average cytoplasmic CAV1 levels (50.7\% vs. 26.8\%, p =0.002, Fisher's exact test). Moreover, Kaplan-Meier analysis disclosed significant differences in overall and tumor specific survival for patients with higher and lower than average cytoplasmic CAV1 expression levels, respectively. The calculated 5-year survival rates for patients with high vs. low cytoplasmic CAV1 levels (i.e. staining intensity $0-3$ vs. $\geq 4$ ) were $51.4 \%$ vs. $75.2 \%$ for overall survival ( $\mathrm{p}=0.001, \log$ rank) and $55.3 \%$ vs. $80.1 \%$ for disease specific survival ( $\mathrm{p}=0.001, \log$ rank), respectively (Figures 1 and 2). Furthermore, tumor-specific survival of patients with a CAV1 staining score of 4 or 5 $(\mathrm{n}=19)$ in the tumor cell cytoplasm was significantly shorter compared with that of patients with a score of $2-3(\mathrm{n}=38)$ and even more $0-1(\mathrm{n}=112)$ with 5 -year tumor specific survival rate of $26.3 \%, 60.0 \%$, and $80.1 \%$, respectively ( $\mathrm{p}<0.001$, Mantel-Cox; additional file 3 , figure S3).

In contrast, using univariate analysis, high membranous CAV1 failed to significantly predict tumor associated death rates during follow up (42.9\% vs. 33.6\%, p $=0.25$, Fisher's exact test). Accordingly, neither overall nor tumor specific Kaplan-Meier survival were significantly associated with CAV1 expression located in the tumor cell membranes $(\mathrm{p}=0.41$ and 0.24 , respectively; Figures 3 and 4). Furthermore, tumor-specific survival of patients with a CAV1 staining score of 2 or $3(n=50)$ in the tumor cell membrane was slightly but insignificantly shorter compared with that of patients with a score of 1 $(\mathrm{n}=85)$ or $0(\mathrm{n}=34)$ with a 5 -year tumor specific survival rate of $61.9 \%, 72.8 \%$, and $72.7 \%$, respectively $(\mathrm{p}=$ 0.56, Mantel-Cox; additional file 4, figure S4).

Applying multivariable Cox regression analysis, including age, sex, stage, metastasis status, and tumor grade, in contrast to CAV1 cell membrane expression $(\mathrm{p}=0.51$; HR 1.17, 95\% CI 0.73-1.87, and $\mathrm{p}=0.34$; HR 1.31, 95\% CI 0.75-2.30), a high CAV1 protein expression level in the tumor cell cytoplasm could be identified as an independent poor prognostic marker of both overall ( $\mathrm{p}=$ 0.022 ; HR 1,74, 95\% CI 1.08-2.80) and tumor specific survival ( $\mathrm{p}=0.026$; HR 1.95, 95\% CI 1.08-3.51) in RCC patients (table 3$)$.

\section{Discussion}

Increased CAV1 expression has been reported to be associated with progression of papillary carcinoma of the thyroid, high-grade bladder cancer, poor prognosis of 
Table 1 Association of different patient and tumor specific characteristics with CAV1 protein expression in the tumor cytoplasm.

\begin{tabular}{|c|c|c|c|c|}
\hline Variable & CAV1 in tumor cytoplasm $\leq$ median & CAV1 in tumor cytoplasm $>$ median & p-value & Test \\
\hline Age (mean; \pm SD) & $60.4 \pm 11.5$ years & $59.3 \pm 11.1$ years & 0.40 & t-test \\
\hline Sex & & & 0.04 & Fisher's exact \\
\hline female & $79(50.6 \%)$ & $51(38.3 \%)$ & & \\
\hline male & $77(49.4 \%)$ & $82(61.7 \%)$ & & \\
\hline Stage (TNM 2002) & & & 0.54 & $\mathrm{Chi}^{2}$ \\
\hline pT1 & $5(3.2 \%)$ & $3(2.3 \%)$ & & \\
\hline pT2 & $86(55.1 \%)$ & $64(48.1 \%)$ & & \\
\hline pT3 & $58(37.2 \%)$ & $57(42.9 \%)$ & & \\
\hline pT4 & $7(4.5 \%)$ & $9(6.7 \%)$ & & \\
\hline $\mathrm{LN}$ metastasis ${ }^{1}$ & & & 0.04 & Fisher's exact \\
\hline pNO & $78(89.7 \%)$ & $70(77.8 \%)$ & & \\
\hline $\mathrm{pN}+$ & $9(10.3 \%)$ & $20(22.2 \%)$ & & \\
\hline Pulmonal/visceral metastasis ${ }^{1}$ & & & 0.23 & Fisher's exact \\
\hline Mo & $124(82.7 \%)$ & $93(76.2 \%)$ & & \\
\hline $\mathrm{M}+$ & $26(17.3 \%)$ & $29(23.8 \%)$ & & \\
\hline Grade & & & 0.04 & $\mathrm{Chi}^{2}$ \\
\hline G1 & $30(21.6 \%)$ & $20(17.7 \%)$ & & \\
\hline $\mathrm{G} 2$ & $103(74.1 \%)$ & 78 (69.0\%) & & \\
\hline $\mathrm{G} 3 / 4$ & $6(4.3 \%)$ & 15 (13.3\%) & & \\
\hline
\end{tabular}

1 at time of renal surgery.

Abbreviations: CAV1 = caveolin 1, RCC = renal cell carcinoma, SD = standard deviation, $\mathrm{LN}=$ lymph node.

pancreas cancer, and lymph node metastasis in esophageal squamous cell carcinoma. Moreover, increased CAV1 expression has been reported to be associated with various pathological parameters, including higher
Gleason score in prostate cancer, lymph node metastasis and positive surgical margins, and it has been shown to be an independent prognostic marker for progression in clinically localized prostate cancer [23]. These studies

Table 2 Association of different patient and tumor specific characteristics with CAV1 protein expression in tumor membranes.

\begin{tabular}{|c|c|c|c|c|}
\hline Variable & CAV1 in tumor membranes $\leq$ median & CAV1 in tumor membranes $>$ median & p-value & Test \\
\hline Age (mean; \pm SD) & $59.9 \pm 11.7$ years & $59.8 \pm 10.8$ years & 0.99 & t-test \\
\hline Sex & & & 0.03 & Fisher's exact \\
\hline female & $87(50.3 \%)$ & $43(37.1 \%)$ & & \\
\hline male & $86(49.7 \%)$ & $73(62.9 \%)$ & & \\
\hline Stage (TNM 2002) & & & 0.54 & $\mathrm{Chi}^{2}$ \\
\hline pT1 & $4(2.3 \%)$ & $4(3.4 \%)$ & & \\
\hline pT2 & $91(52.6 \%)$ & $59(50.9 \%)$ & & \\
\hline pT3 & $66(38.2 \%)$ & $49(42.2 \%)$ & & \\
\hline pT4 & $12(6.9 \%)$ & $4(3.4 \%)$ & & \\
\hline LN metastasis $^{1}$ & & & 1.00 & Fisher's exact \\
\hline pNO & $86(83.5 \%)$ & $62(83.8 \%)$ & & \\
\hline $\mathrm{pN}+$ & $17(16.5 \%)$ & $12(16.2 \%)$ & & \\
\hline Pulmonal/visceral metastasis ${ }^{1}$ & & & 0.54 & Fisher's exact \\
\hline MO & $133(81.1 \%)$ & $84(77.8 \%)$ & & \\
\hline $\mathrm{M}+$ & $31(18.9 \%)$ & $24(22.2 \%)$ & & \\
\hline Grade & & & 0.28 & $\mathrm{Chi}^{2}$ \\
\hline G1 & 30 (20.2\%) & 20 (19.4\%) & & \\
\hline G2 & $110(73.8 \%)$ & 71 (68.9\%) & & \\
\hline $\mathrm{G} 3 / 4$ & 9 (6.0\%) & $12(11.7 \%)$ & & \\
\hline
\end{tabular}

${ }^{1}$ at time of renal surgery.

Abbreviations: $\mathrm{CAV} 1$ = caveolin $1, \mathrm{RCC}=$ renal cell carcinoma, SD = standard deviation, $\mathrm{LN}=$ lymph node. 


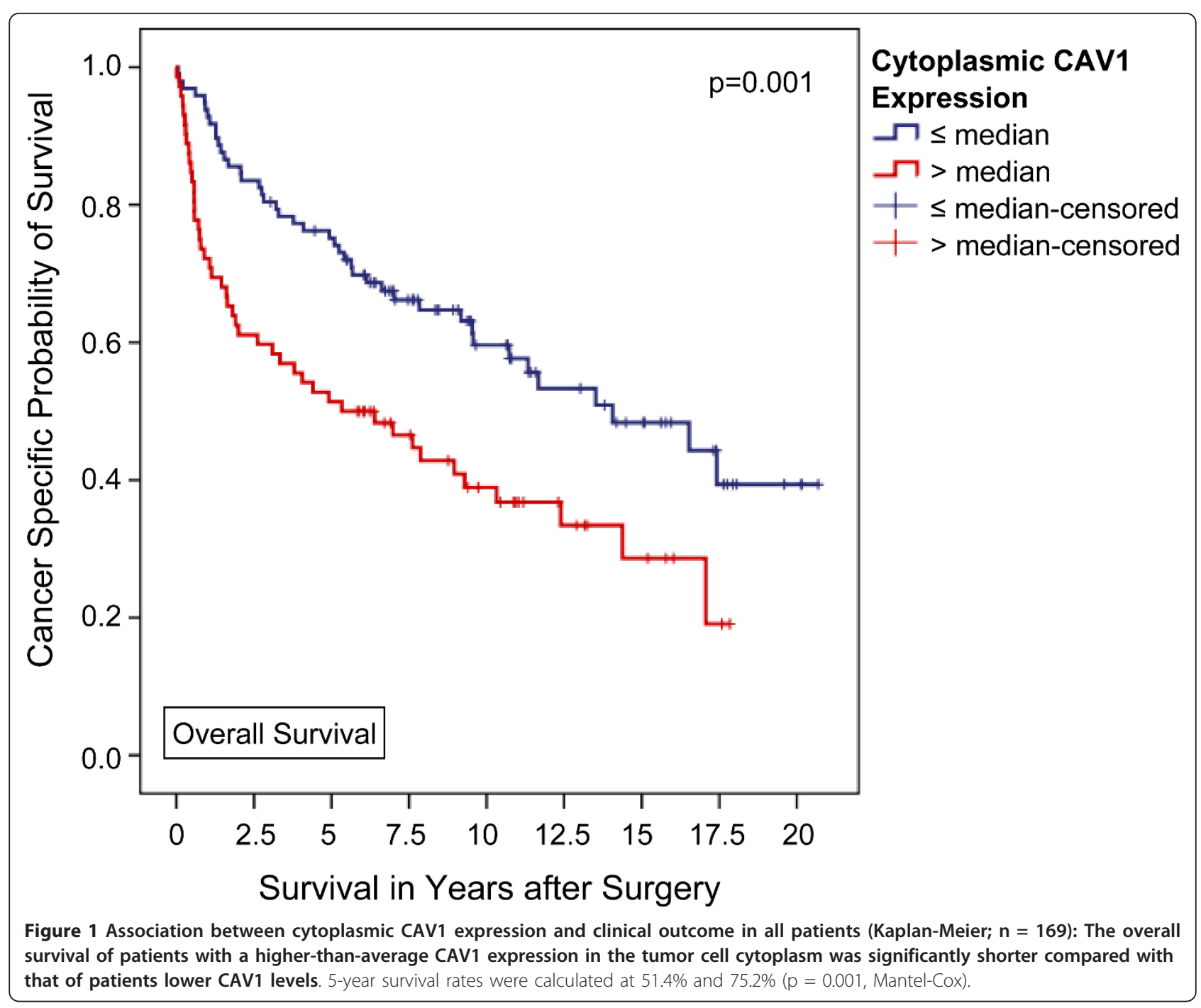

indicate that CAV1 functions as a tumor metastasis and progression-promoting molecule. On the other hand, CAV1 has also been implicated in the inhibition of cancer progression. For example, CAV1 expression is frequently lost in colon cancer, ovarian cancer, lung cancer and sarcoma [9,24-27]. Therefore, the physiological role of CAV1 in cancer cells is quite complicated depending e.g. on the type of cancer and the tumor origin. Several studies using tissue microarry (TMA) and immunostaining have shown similar associations between the increased expression of CAV1 and clinicopathological parameters in RCC as described in prostate cancer. A major difference between prostate and kidney tissue is that CAV1 is present at high levels in normal kidney tissue independent of CAV1 levels in tumor tissue but not in normal prostate tissue [23].

Several groups of investigators have studied the prognostic significance of caveolin-1 protein expression.
Horiguchi et al. [28] reported that in clear cell RCC patients increased caveolin-1 expressions also correlated with tumor aggressiveness. Campbell et al. [13] also described that higher caveolin-1 expression was correlated with shorter survival in 69 patients with clear cell histology.

Previously, we were able to show that CAV1 mRNA expression is higher in RCC compared to normal renal tissue and increases with tumour stage [29]. In the present study, which until today is the largest study cohort with a sufficient follow-up period, Caveolin 1 protein expression was correlated with clinico-pathological parameters and survival in patients with clear cell RCC. Kaplan-Meier analysis disclosed significant differences in overall and tumor specific 5-year survival for patients with higher and lower than average cytoplasmic CAV1 expression levels, i.e. $51.4 \%$ vs. $75.2 \%$ for overall survival and $55.3 \%$ vs. $80.1 \%$ for disease specific survival, 


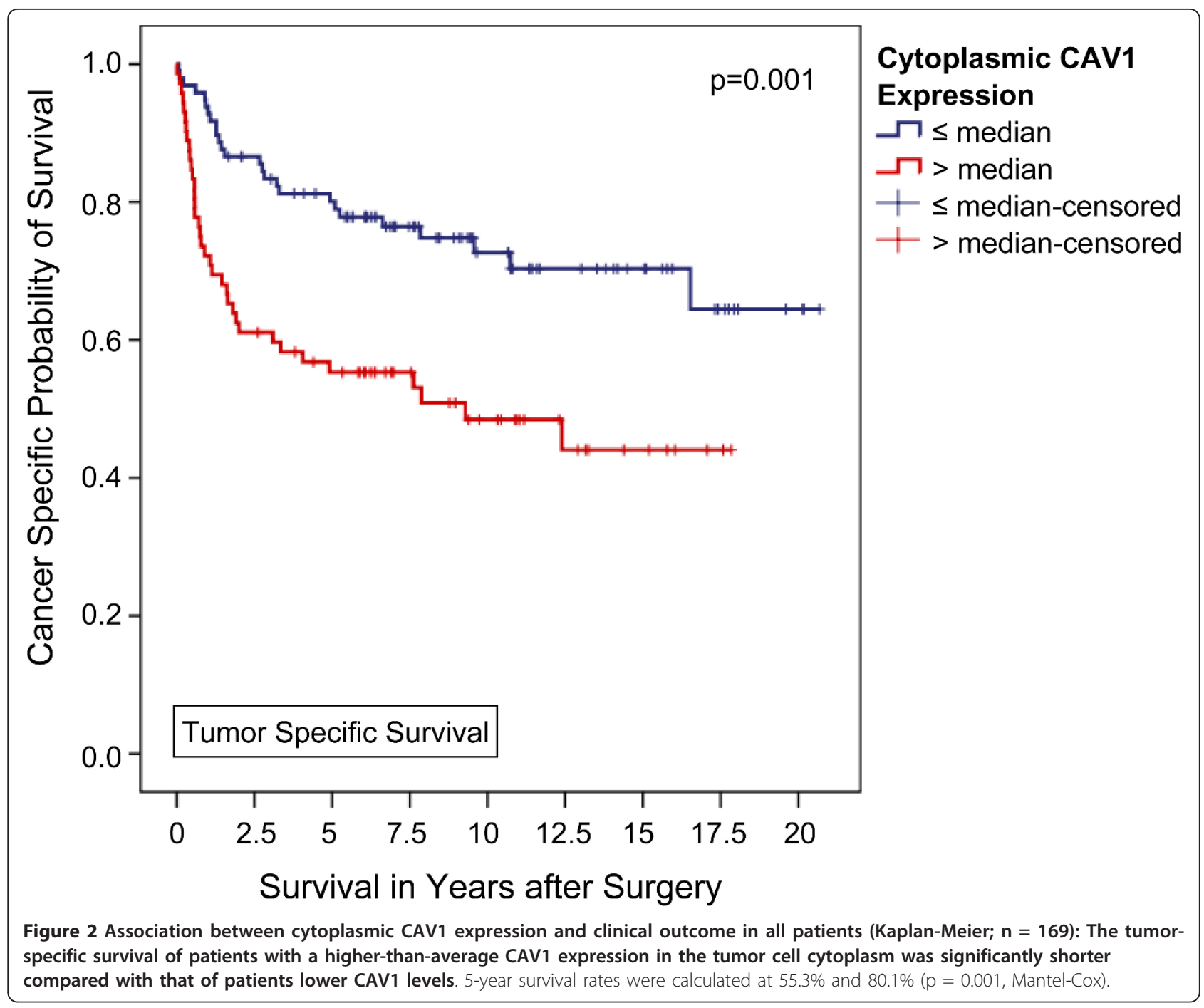

respectively. This supports the hypothesis that CAV1 plays a potential role in renal carcinogenesis or at least RCC progression. In contrast, a study by Tamaskar et al. with 22 RCC patients there was no correlation between membranous or cytoplasmic caveolin-1 expression and other clinical parameters, with membranous caveolin-1 expression being detected predominantly in clear cell RCC. Mete et al. [30] studied 112 renal tumors with different histological subtypes also using polyclonal rabbit antihuman CAV1 antibody and observed that staining was mainly cytoplasmic in all tumor groups. Also Campbell et al. [13] showed in that staining is predominantly found in the tumor cell cytoplasm of RCC patients. We were able to confirm these results as CAV1 expression was detected in the tumor cell cytoplasm of $242(83.7 \%)$ and the cell membrane of 232 (80.3\%) patients with clear cell RCC, the cell nuclei were negative in all patients' tumor specimens. Furthermore, high CAV1 protein expression level in the tumor cell cytoplasm could be identified as an independent poor prognostic marker.

The reasons for these findings are still unclear, as CAV1 expression would be expected to be mainly found on the cell surface. Tahir et al. [31] where able to show that in prostate cancer cell lines CAV1 is secreted in response to androgens and glucocorticoids leading to survival and clonal growth of these cells and thereby contributing to their metastatic potential and androgen insensitivity. Tahir et al was able to show that elevated preoperative levels of serum CAV1 predicts decreased time to cancer recurrence [32]. Adapted from these results, one explanation for the cytoplasmatic expression of CAV1 in clear cell RCC might be that within the transformed cells, CAV1 is rerouted into the secretory pathway of these cells, and that the cytoplasmatic CAV1 accumulation may contribute to the transformed 


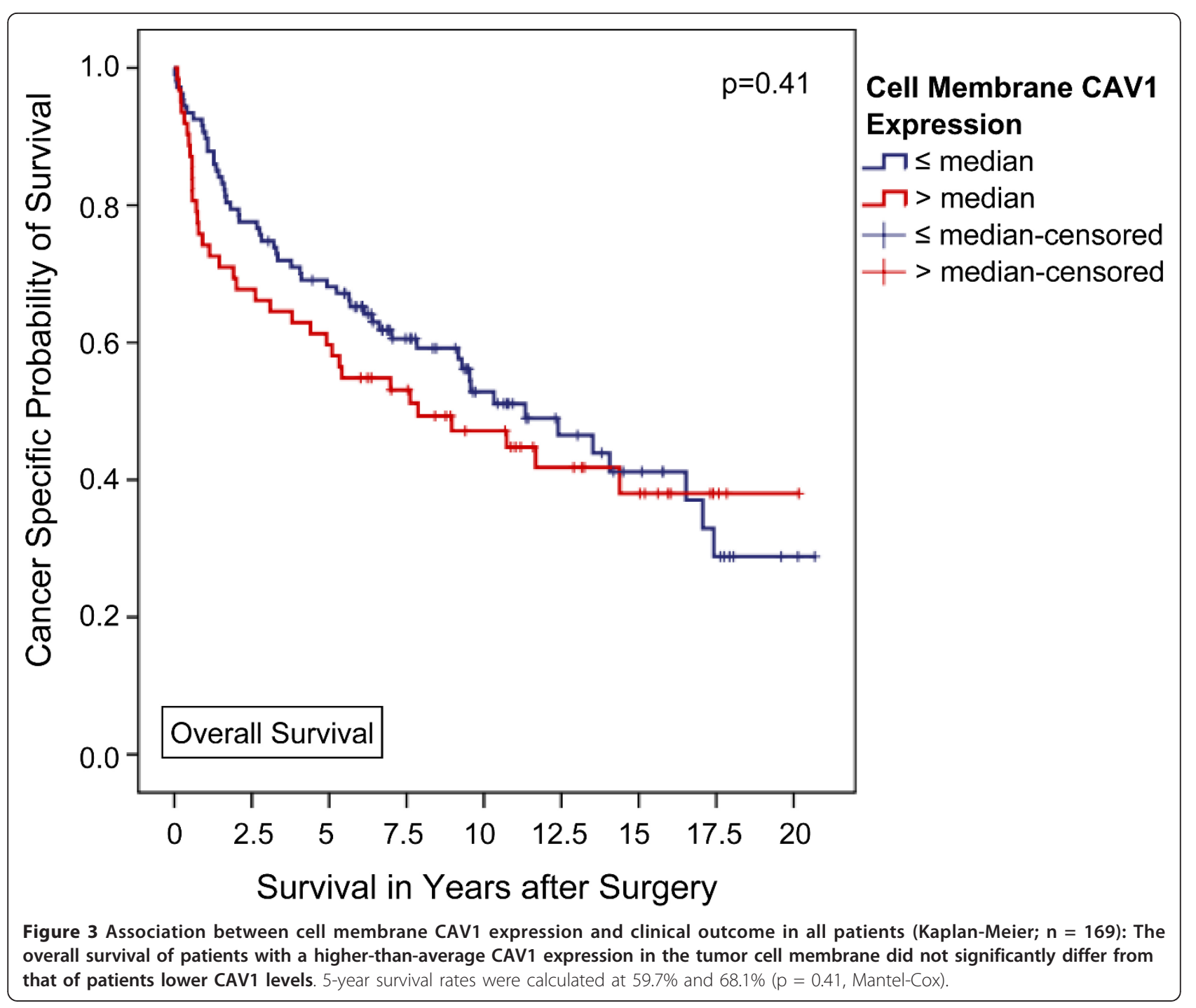

phenotype. Furthermore, Puyraimond et al. [33] have shown that CAV1 interacts and potentiates the activity of metalloproteinases; other studies have shown the same effect on urokinase receptors leading to the conclusion that CAV1 may serve as an important intercellular signaling molecule that is capable of inducing progression, invasiveness and vascularisation of renal tumors.

A further important fact is that the etiology of most cancers does not reflect alterations in a single gene, but rather the functional loss or induction of a series of key regulatory proteins that, in combination, disrupts the normal regulation of the cell cycle and subsequently leads to uncontrolled cell growth [34]. CAV1 has been recognized to potentiate $\mathrm{AKT}$ activity in a variety of model systems. Campbell et al. [35] revealed that when CAV1 is co expressed with pAKT, pmTOR, pS6 or p4E$\mathrm{BP} 1$ within the primary tumor, time to relapse was significantly reduced compared with when either of the individual variables were expressed alone. They have suggested that the co expression of CAV1 and activated components of the AKT/mTOR pathway represents a 'linked molecular signature' that identifies patients with localized RCC that are at high risk of developing metastatic disease that warrants greater postoperative surveillance. Evaluation of the expression status of both CAV1 and mTOR pathway components in these tumors may help to predict tumor response to novel pathway specific therapies, hence allowing appropriate selection of treatment for individual patients. Interestingly, CAV1 has been identified as a molecular target of bortezomib, which has many molecular targets including proteins related to apoptosis, growth signaling/cell cycle heatshock proteins, and the proteasome pathway. A Phase II trial in patients with advanced RCC showed moderate clinical efficacy for bortezomib [36]. 


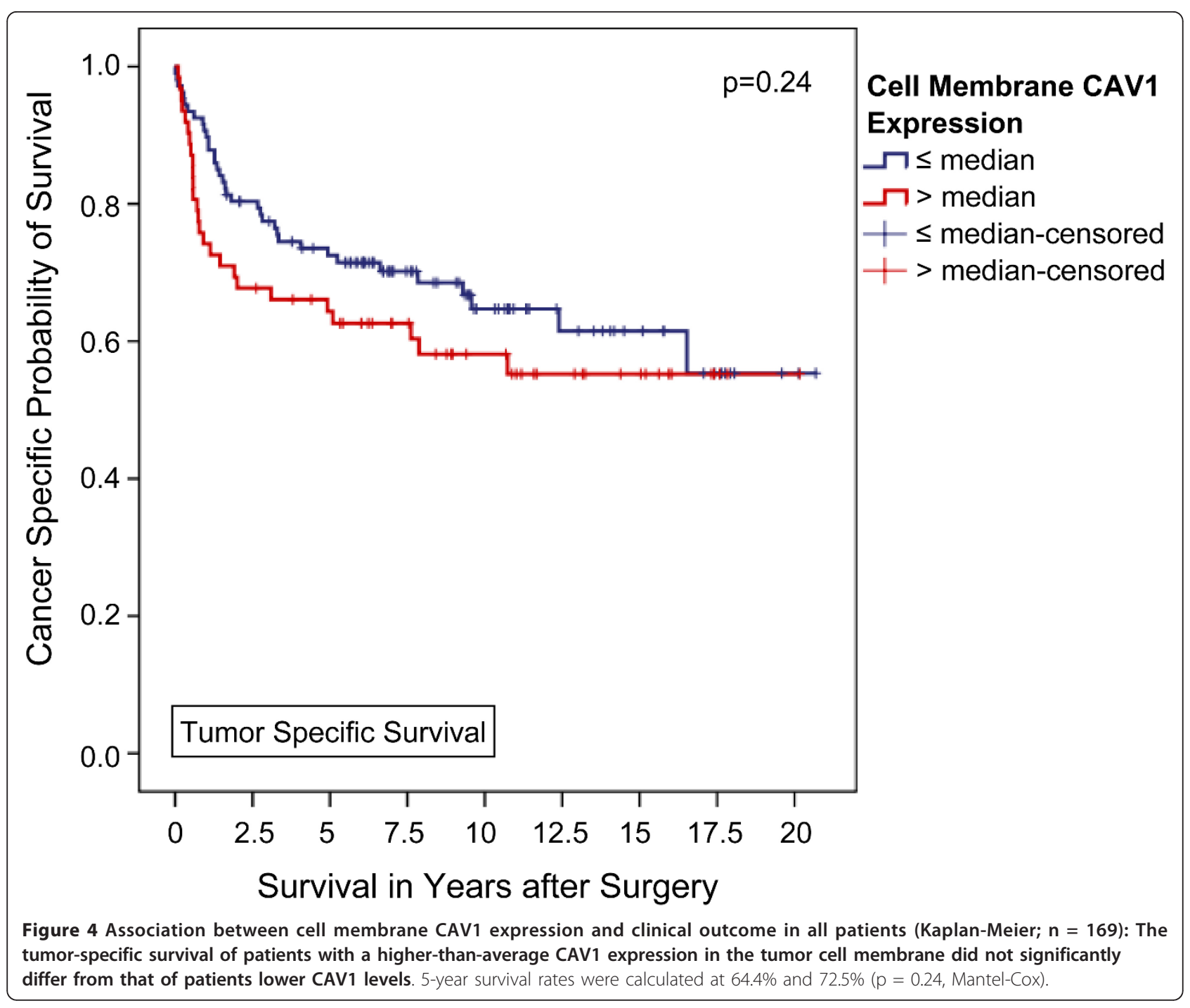

Table 3 Multivariable Cox regression analysis identified an elevated CAV1 staining value in the tumor cytoplasm as an independent predictor of tumor specific survival.

\begin{tabular}{|c|c|c|c|c|}
\hline \multirow[b]{2}{*}{ Variable } & \multicolumn{2}{|c|}{ CAV1 expression in the tumor cell cytoplasm } & \multicolumn{2}{|c|}{ CAV1 expression in the tumor cell membrane } \\
\hline & HR $(95 \% \mathrm{Cl})$ & p-value & HR $(95 \% \mathrm{Cl})$ & p-value \\
\hline Age & $1.01(0.99-1.01)$ & 0.35 & $1.01(0.98-1.03)$ & 0.71 \\
\hline Sex & & 0.45 & & 0.44 \\
\hline female & 1 (Reference) & & 1 (Reference) & \\
\hline male & $1.26(0.70-2.28)$ & & $1.27(0.69-2.23)$ & \\
\hline T-Stage & & 0.43 & & 0.19 \\
\hline pT1 & 1 (Reference) & & 1 (Reference) & \\
\hline pT2 & $1.43(0.19-10.86)$ & 0.73 & $1.43(0.19-10.92)$ & 0.73 \\
\hline pT3 & $2.28(0.30-17.58)$ & 0.43 & $2.64(0.35-20.28)$ & 0.35 \\
\hline pT4 & $2.97(0.27-33.25)$ & 0.38 & $3.39(0.30-37.89)$ & 0.32 \\
\hline Metastatic disease & & $<0.001$ & & $<0.001$ \\
\hline $\mathrm{N} / \mathrm{MO}$ & 1 (Reference) & & 1 (Reference) & \\
\hline $\mathrm{N} / \mathrm{M}+$ & $5.04(2.66-9.54)$ & & $4.88(2.60-9.16)$ & \\
\hline
\end{tabular}


Table 3 Multivariable Cox regression analysis identified an elevated CAV1 staining value in the tumor cytoplasm as an independent predictor of tumor specific survival. (Continued)

\begin{tabular}{lcccc}
\hline Differentiation & $<0.001$ & & \\
G1 & 1 (Reference) & & 1 (Reference) & \\
G2 & $2.75(1.07-7.10)$ & 0.04 & $2.55(0.99-6.55)$ & 0.05 \\
G3/4 & $12.02(3.54-40.85)$ & $<0.001$ & $12.29(3.60-41.98)$ & $<0.001$ \\
CAV1 expression level & & 0.03 & 1 (Reference) & \\
$\quad \leq$ median & 1 (Reference) & & $1.31(0.75-2.30)$ \\
$\quad>$ median & $1.95(1.08-3.51)$ & & \\
\hline
\end{tabular}

\section{Conclusion}

We were able to show that caveolin-1 protein expression is a predictor of poor disease-free survival in clear cell RCC, suggesting that cell signaling pathways involving caveolin-1 may be of importance in tumor progression. Furthermore, the strength of the association with poor prognosis suggests that CAV1 is likely to be a useful prognostic marker. Therefore, our data encourage further investigations to enlighten the role of CAV1 in tumour progression and to assess its function as prognostic marker for clinical use in serum and/or urine.

\section{Additional material}

Additional file 1: Figure S1. Caveolin-1 staining of peripheral endothelial cells was used as the positive controls. With no staining reaction of the membrane, cytoplasm and nucleus of the tumor cells.

Additional file 2: Figure S2. Strong membranous Caveolin-1 expression.

Additional file 3: Figure S3. Association between cytoplasmic CAV1 expression and clinical outcome in all patients (Kaplan-Meier; $n=169$ ) focusing on the individual cellular maximum staining score: The tumorspecific survival of patients with a CAV1 staining score of 4 or $5(n=19)$ in the tumor cell cytoplasm was significantly shorter compared with that of patients with a score of 2-3 $(n=38)$ and even more $0-1(n=112)$. 5year tumor specific survival rate were calculated at $26.3 \%, 60.0 \%$, and 80.1\% ( $p<0.001$, Mantel-Cox)

Additional file 4: Figure S4. Association between cell membrane CAV1 expression and clinical outcome in all patients (Kaplan-Meier; $n=169$ ) focusing on the individual cellular maximum staining score: The tumorspecific survival of patients with a CAV1 staining score of 2 or $3(n=50)$ in the tumor cell membrane was slightly but insignificantly shorter compared with that of patients with a score of $1(n=85)$ or $0(n=34)$. 5 -year tumor specific survival rate were calculated at $61.9 \%, 72.8 \%$, and $72.7 \%$ ( $p=0.56$, Mantel-Cox)

\section{Author details}

'Department of Urology, Hannover Medical School, (Carl-Neuberg-Strasse 1), Hannover, (30625), Germany. ²Department of Urology, Ulm-University Medical School, (Prittwitzstrasse 43), Ulm, (89075), Germany. ${ }^{3}$ Department of Pathology, Hannover Medical School, (Carl-Neuberg-Strasse 1), Hannover, (30625), Germany.

\section{Authors' contributions}

SW designed the study, was part of the acquisition, analysis and interpretation of data and drafted the manuscript. AJS performed the statistical analysis and drafted the manuscript. HB and GV carried out the immunoassays and evaluation. HE was part of the data acquisition. WT evaluated the pathological stages. MAK and JS were responsible for the supervision. All authors read and approved the final manuscript.

\section{Competing interests}

The authors declare that they have no competing interests.

Received: 27 June 2011 Accepted: 7 December 2011

Published: 7 December 2011

\section{References}

1. Schrader AJ, Sevinc S, Olbert PJ, Hegele A, Varga Z, Hofmann R: [Genderspecific characteristics and survival of renal cell carcinoma]. Der Urologe Ausg 2008, 47(9):1182, 1184-1186

2. Tamaskar I, Choueiri TK, Sercia L, Rini B, Bukowski R, Zhou M: Differential expression of caveolin-1 in renal neoplasms. Cancer 2007, 110(4):776-782.

3. Engelman JA, Wykoff CC, Yasuhara S, Song KS, Okamoto T, Lisanti MP: Recombinant expression of caveolin-1 in oncogenically transformed cells abrogates anchorage-independent growth. The Journal of biological chemistry 1997, 272(26):16374-16381.

4. Engelman JA, Zhang XL, Galbiati F, Lisanti MP: Chromosomal localization, genomic organization, and developmental expression of the murine caveolin gene family (Cav-1, -2 , and -3 ). Cav-1 and Cav-2 genes map to a known tumor suppressor locus (6-A2/7q31). FEBS letters 1998, 429(3):330-336.

5. Engelman JA, Zhang XL, Lisanti MP: Genes encoding human caveolin-1 and -2 are co-localized to the D7S522 locus (7q31.1), a known fragile site (FRA7G) that is frequently deleted in human cancers. FEBS letters 1998, 436(3):403-410

6. Engelman JA, Zhang XL, Lisanti MP: Sequence and detailed organization of the human caveolin-1 and -2 genes located near the D7S522 locus (7q31.1). Methylation of a CpG island in the $5^{\prime}$ promoter region of the caveolin-1 gene in human breast cancer cell lines. FEBS letters 1999, 448(2-3):221-230.

7. Furuchi T, Anderson RG: Cholesterol depletion of caveolae causes hyperactivation of extracellular signal-related kinase (ERK). The Journal of biological chemistry 1998, 273(33):21099-21104.

8. Galbiati F, Volonte D, Engelman JA, Watanabe G, Burk R, Pestell RG, Lisanti MP: Targeted downregulation of caveolin-1 is sufficient to drive cell transformation and hyperactivate the p42/44 MAP kinase cascade. The EMBO journal 1998, 17(22):6633-6648.

9. Koleske AJ, Baltimore D, Lisanti MP: Reduction of caveolin and caveolae in oncogenically transformed cells. Proceedings of the National Academy of Sciences of the United States of America 1995, 92(5):1381-1385.

10. Lee SW, Reimer CL, Oh P, Campbell DB, Schnitzer JE: Tumor cell growth inhibition by caveolin re-expression in human breast cancer cells. Oncogene 1998, 16(11):1391-1397.

11. Sager R, Sheng S, Anisowicz A, Sotiropoulou G, Zou Z, Stenman G, Swisshelm K, Chen Z, Hendrix MJ, Pemberton P, et al: RNA genetics of breast cancer: maspin as paradigm. Cold Spring Harbor symposia on quantitative biology 1994, 59:537-546.

12. Scherer PE, Okamoto T, Chun M, Nishimoto I, Lodish HF, Lisanti MP: Identification, sequence, and expression of caveolin-2 defines a caveolin gene family. Proceedings of the National Academy of Sciences of the United States of America 1996, 93(1):131-135.

13. Campbell L, Gumbleton M, Griffiths DF: Caveolin-1 overexpression predicts poor disease-free survival of patients with clinically confined renal cell carcinoma. British journal of cancer 2003, 89(10):1909-1913.

14. Mengel M, Kreipe H, von Wasielewski R: Rapid and large-scale transition of new tumor biomarkers to clinical biopsy material by innovative tissue 
microarray systems. Appl Immunohistochem Mol Morphol 2003, 11(3):261-268.

15. Guinan P, Sobin LH, Algaba F, Badellino F, Kameyama S, MacLennan G, Novick A: TNM staging of renal cell carcinoma: Workgroup No. 3. Union International Contre le Cancer (UICC) and the American Joint Committee on Cancer (AJCC). Cancer 1997, 80(5):992-993.

16. Fuhrman SA, Lasky LC, Limas C: Prognostic significance of morphologic parameters in renal cell carcinoma. The American journal of surgical pathology 1982, 6(7):655-663.

17. Stenzl A, deKernion JB: Pathology, biology, and clinical staging of renal cell carcinoma. Seminars in oncology 1989, 16(1 Suppl 1):3-11.

18. Theodorescu D, Broder SR, Boyd JC, Mills SE, Frierson HF Jr: Cathepsin D and chromogranin $A$ as predictors of long term disease specific survival after radical prostatectomy for localized carcinoma of the prostate. Cancer 1997, 80(11):2109-2119.

19. Merseburger AS, Hennenlotter J, Simon P, Muller CC, Kuhs U, KnuchelClarke R, Moul JW, Stenzl A, Kuczyk MA: Activation of the PKB/Akt pathway in histological benign prostatic tissue adjacent to the primary malignant lesions. Oncol Rep 2006, 16(1):79-83.

20. Merseburger AS, Kramer MW, Hennenlotter J, Simon P, Knapp J, Hartmann JT, Stenzl A, Serth J, Kuczyk MA: Involvement of decreased Galectin-3 expression in the pathogenesis and progression of prostate cancer. The Prostate 2008, 68(1):72-77.

21. Tezval H, Jurk S, Atschekzei F, Serth J, Kuczyk MA, Merseburger AS: The involvement of altered corticotropin releasing factor receptor 2 expression in prostate cancer due to alteration of anti-angiogenic signaling pathways. The Prostate 2008.

22. Peters I, Rehmet K, Wilke N, Kuczyk MA, Hennenlotter J, Eilers T, Machtens S , Jonas $U$, Serth J: RASSF1A promoter methylation and expression analysis in normal and neoplastic kidney indicates a role in early tumorigenesis. Molecular cancer 2007, 6:49.

23. Yang G, Truong LD, Wheeler TM, Thompson TC: Caveolin-1 expression in clinically confined human prostate cancer: a novel prognostic marker. Cancer research 1999, 59(22):5719-5723.

24. Bender FC, Reymond MA, Bron C, Quest AF: Caveolin-1 levels are downregulated in human colon tumors, and ectopic expression of caveolin-1 in colon carcinoma cell lines reduces cell tumorigenicity. Cancer research 2000, 60(20):5870-5878.

25. Racine C, Belanger M, Hirabayashi H, Boucher M, Chakir J, Couet J: Reduction of caveolin 1 gene expression in lung carcinoma cell lines. Biochemical and biophysical research communications 1999, 255(3):580-586.

26. Wiechen K, Diatchenko L, Agoulnik A, Scharff KM, Schober H, Arlt K, Zhumabayeva B, Siebert PD, Dietel M, Schafer R, et al: Caveolin-1 is downregulated in human ovarian carcinoma and acts as a candidate tumor suppressor gene. The American journal of pathology 2001, 159(5):1635-1643.

27. Wiechen K, Sers C, Agoulnik A, Arlt K, Dietel M, Schlag PM, Schneider U: Down-regulation of caveolin-1, a candidate tumor suppressor gene, in sarcomas. The American journal of pathology 2001, 158(3):833-839.

28. Horiguchi A, Asano T, Asakuma J, Asano T, Sumitomo M, Hayakawa M: Impact of caveolin-1 expression on clinicopathological parameters in renal cell carcinoma. The Journal of urology 2004, 172(2):718-722.

29. Waalkes S, Eggers H, Blasig H, Atschekzei F, Kramer MW, Hennenlotter J, Trankenschuh W, Stenzl A, Serth J, Schrader AJ, et al: Caveolin 1 mRNA is overexpressed in malignant renal tissue and might serve as a novel diagnostic marker for renal cancer. Biomarkers in medicine 5(2):219-225.

30. Mete O, Kilicaslan I, Gulluoglu MG, Uysal V: Can renal oncocytoma be differentiated from its renal mimics? The utility of anti-mitochondrial, caveolin 1, CD63 and cytokeratin 14 antibodies in the differential diagnosis. Virchows Arch 2005, 447(6):938-946.

31. Tahir SA, Yang G, Ebara S, Timme TL, Satoh T, Li L, Goltsov A, Ittmann M, Morrisett JD, Thompson TC: Secreted caveolin-1 stimulates cell survival/ clonal growth and contributes to metastasis in androgen-insensitive prostate cancer. Cancer research 2001, 61(10):3882-3885.

32. Tahir SA, Frolov A, Hayes TG, Mims MP, Miles BJ, Lerner SP, Wheeler TM, Ayala G, Thompson TC, Kadmon D: Preoperative serum caveolin-1 as a prognostic marker for recurrence in a radical prostatectomy cohort. Clin Cancer Res 2006, 12(16):4872-4875.

33. Puyraimond A, Fridman R, Lemesle M, Arbeille B, Menashi S: MMP-2 colocalizes with caveolae on the surface of endothelial cells. Experimental cell research 2001, 262(1):28-36.
34. Loeb LA, Loeb KR, Anderson JP: Multiple mutations and cancer. Proceedings of the National Academy of Sciences of the United States of America 2003, 100(3):776-781.

35. Campbell L, Jasani B, Edwards K, Gumbleton M, Griffiths DF: Combined expression of caveolin-1 and an activated AKT/mTOR pathway predicts reduced disease-free survival in clinically confined renal cell carcinoma. British journal of cancer 2008, 98(5):931-940.

36. Kondagunta GV, Drucker B, Schwartz L, Bacik J, Marion S, Russo P, Mazumdar M, Motzer RJ: Phase II trial of bortezomib for patients with advanced renal cell carcinoma. J Clin Oncol 2004, 22(18):3720-3725.

\section{Pre-publication history}

The pre-publication history for this paper can be accessed here: http://www.biomedcentral.com/1471-2490/11/25/prepub

\section{doi:10.1186/1471-2490-11-25}

Cite this article as: Steffens et al:: Caveolin 1 protein expression in renal cell carcinoma predicts survival. BMC Urology 2011 11:25.

\section{Submit your next manuscript to BioMed Central and take full advantage of:}

- Convenient online submission

- Thorough peer review

- No space constraints or color figure charges

- Immediate publication on acceptance

- Inclusion in PubMed, CAS, Scopus and Google Scholar

- Research which is freely available for redistribution 